\title{
THE CONTRIBUTION OF GIS TO DISPLAY AND ANALYZE THE WATER QUALITY DATA COLLECTED BY A WIRELESS SENSOR NETWORK: CASE OF BOUREGREG CATCHMENT, MOROCCO
}

\author{
S. Boubakri ${ }^{\text {a }}$ H. Rhinane ${ }^{\text {a }}$ \\ ${ }^{a}$ Geosciences Laboratory, Faculty of Ain Chock, Hassan II University, Casablanca, Morocco - said.boubakri@gmail.com
}

KEY WORDS: Water quality, Wireless sensor network, GIS, Geographic Information System, Catchment

\begin{abstract}
:
The monitoring of water quality is, in most cases, managed in the laboratory and not on real time bases. Besides this process being lengthy, it doesn't provide the required specifications to describe the evolution of the quality parameters that are of interest. This study presents the integration of Geographic Information Systems (GIS) with wireless sensor networks (WSN) aiming to create a system able to detect the parameters like temperature, salinity and conductivity in a Moroccan catchment scale and transmit information to the support station. This Information is displayed and evaluated in a GIS using maps and spatial dashboard to monitor the water quality in real time.
\end{abstract}

\section{INTRODUCTION}

For the first time, all nations have adopted a binding agreement to counter all climate change consequences. This decision obliges all countries to commit more seriously to achieve the target goal. The city of Marrakech is hosting the next conference, COP22, which is the occasion for all nations to present first evaluation of the measures taken against global warming and greenhouse gas emissions. Water quality is discussed at greater depth because it becomes a big global warning.

Improving the quality of water has been a rapidly growing global concern. In most cases, and as researches show, Poor water quality results from poor management of water, economics and bad agricultural practices (Huma et al. 2102). The major contributors of this situation in Morocco are agriculture, industrial wastes and waste water discharges (Bounouira, 2007).

Water quality monitoring (WQM) is done under several data analysis methods such as satellite based remote sensing of the water bodies. From various surveys done, it has been proposed that regardless of their various limitations, the wireless sensor networks (WSNs), are the most effective and used in current spatial-temporal data collection for the WQM applications (Huma et al. 2102).

A WSN is referred to as a network of autonomous tiny sensorusing wireless devices that keep track of environmental and physical conditions which is wireless. They do this by converting factors like temperature, pressure, humidity and light intensity into electric signals (Ayday, 2009).

The study below describes the integration of WSNs and GIS to create a system that detects and computes the parameters like temperature, salinity and conductivity in a catchment scale (rivers, dams, lakes...) and transmit information via WSN to the support station. This Information is displayed and evaluated in a GIS using maps and spatial dashboard to evaluate the water quality.

\section{MATERIALS \& METHODS}

\subsection{The Study Area}

Bouregreg Watershed is found in Morocco, near Rabat (Fig. 1). SMBA dam, 15 kilometers from the Atlantic Ocean is the outlet in this study. The main rivers are the Grou River, and the Bouregreg River, 260 and $125 \mathrm{~km}$ respectively. The watershed has an area of $9570 \mathrm{~km}^{2}$ and is at an elevation from the southeast mountains to the SMBA outlet.

This is a semi-arid region with temperatures between $11^{\circ} \mathrm{C}$ and $22^{\circ} \mathrm{C}$ annually. Average inflow to the dam is $600 \mathrm{Mm}^{3} /$ year (Fadil et al. 2011).

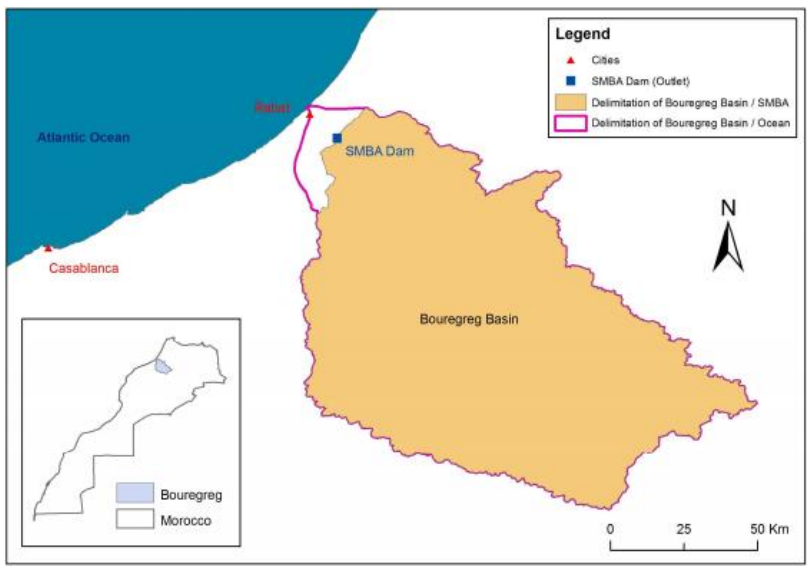

Figure 1.Map of Bouregreg Watershed

\subsection{Factors behind a Wireless Sensor Network}

Recently, major advances in electronic circuits and wireless communication have taken place (Akyildiz et al. 2002a). Following these advancements, research in development of low energy devices that are cheap has been initiated. These devices have the ability to carry out data acquisition tasks. Research along this field of study is what is referred to as the (WSNs) (Lu et al. 2004). 
From the earlier description of a WSN, every wireless device is also referred to as a node and it behaves individually with one or more sensors on it. It also has a transmitter and a receiver which wirelessly communicate with other nodes or with the gateway. This gateway is liable for transmission of sensor data from the sensor patch to a base station responsible for providing WAN connectivity across a local network. The data transmitted is then available for the recipient via a user interface (Mainwaring et al. 2002). The remaining parts of the node are used as the energy source in the battery.

\subsection{Sensor used in this study}

The sensor used in our study is CDT-DIVER. The Diver is comprised of a pressure sensor that measures water pressure, a battery, a temperature sensor and a memory and it can be easily programmed by the user. The drivers and field devices such as laptops communicate through an optical communication.

This driver measures not only the temperature and water levels, but also the electrical conductivity of the water in $\mathrm{mS} / \mathrm{cm}$.

\subsection{Overall system architecture}

As shown in Fig. 2, it is comprised of three main subsystems that will be discussed systematically:

a) Data acquisition: This is a collection of sensors distributed at many points of the study area. These sensors gather any information on the various parameters on the subsystem that are awaiting analyze.

b) Control and communication: This system monitors and has control over the chemical analysis; it then collects the information gathered in this subsystem and finally forwards it to the subsequent subsystem below.

c) Data management: This periodically receives the information from the system described above in (b). This information is worked on, stored then made accessible through the GIS tool. The information can also generate any appropriate warnings as programmed.

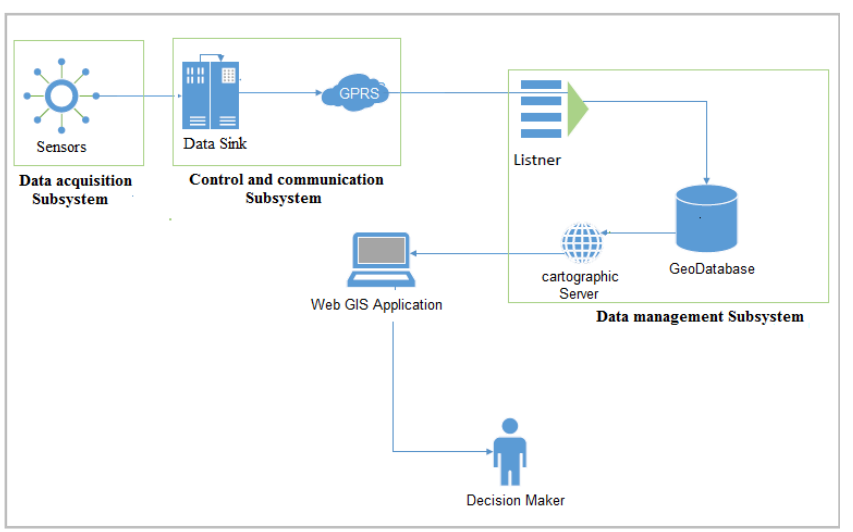

Figure 2.System architecture

\subsection{Software architecture of data management subsystem}

This subsystem is contained in PC architecture with the software below;

- Database manager system is based on the PostgreSQL software and its spatial extension called PostGIS.

There is too category of data in this database: geographic feature classes like catchment limits, rivers, dams, water tables and sensors positions. The other data type is attribute tables that contains measured values by sensors and tables used to administrate the developed GIS.

- A GIS Server based on GeoServer publishes data attained from any source by the use of open standards.

- A web server is an open-source application server used to build, test, and deploy Java EE applications. It uses the GlassFish software.

- User web application. It's developed using JSF Framework, HTML5 and GeoExt - a JavaScript Toolkit for Rich Web Mapping Applications.

This application allows getting maps, reports and statistics. This application can be used in making changes on the system's working parameters. Moreover, with the right permissions, it can be accessed from any device that has an internet connection.

Following is the software architecture of data management subsystem.

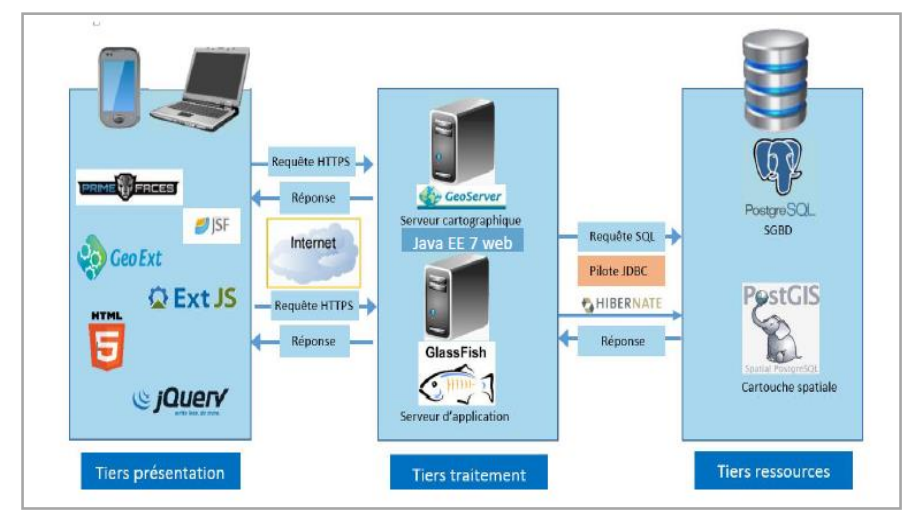

Figure 3. Software architecture of data management subsystem

\subsection{Functional architecture of the GIS application}

Fig 4 represents the functional architecture of the GIS application. It shows all modules used to display, manage and analyze received data from sensors.

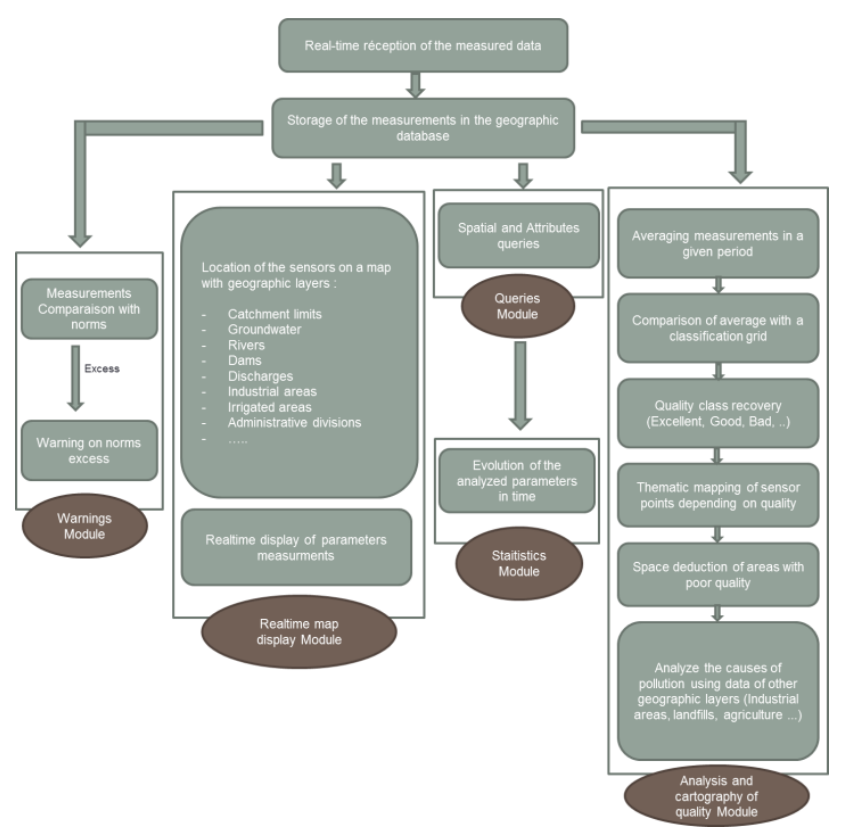

Figure 4. Functional architecture of the GIS application 


\section{RESULTS}

From the study above, the following results were found.

Fig. 5 shows the main interface of the GIS application; it displays a map that contains many superposed layers like catchment limits, rivers, dams, lakes, urban areas ... and the sensors positions with the real-time information about analyzed parameters (Parameter name, Value and Time).

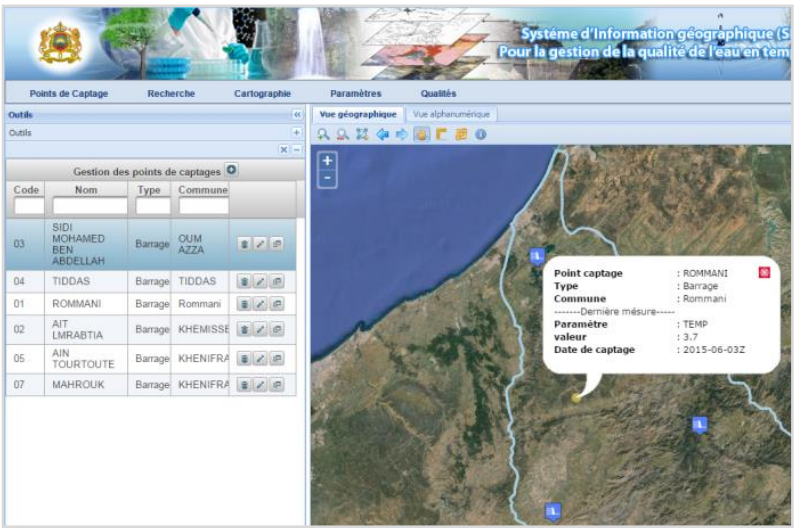

Figure 5. Main interface of the GIS application

The data is collected by the sensors, distributed in catchment unities, transferred at scheduled intervals to the server and then the real-time water quality map of the study area is displayed using the GIS application.

Also, we can easily evaluate large amounts of spatial data by adopting and incorporating the benefits of a spatial dashboard This spatial dashboard shows the evolution of the analyzed parameters represented by maps, data tables and charts with warnings (Fig 6).

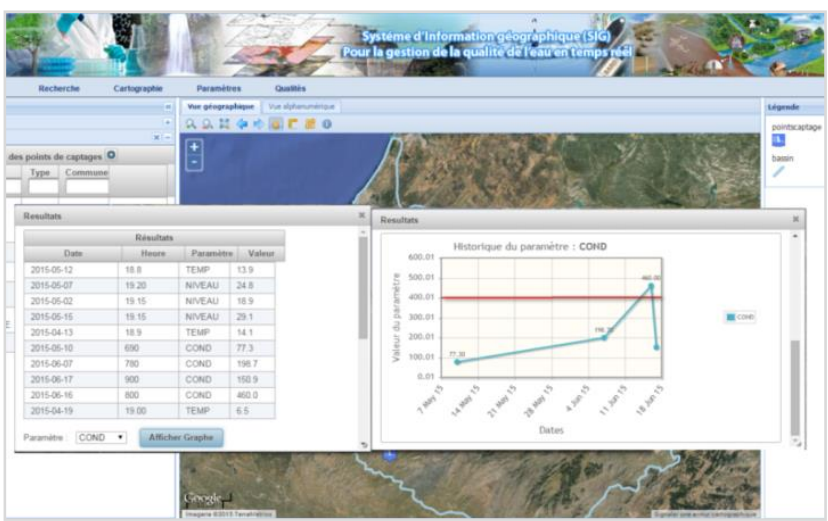

Figure 6. Spatial dashboard

Activities such as increasing/decreasing in pollution, salinization and water flow may cause a change in conductivity observed in the evolution chart.

Finally, after comparing received data between tow dates with a classification grid, the application can generate a thematic map of the water quality for each sensor point (Fig 7). In this case we can see sensor points on the map colored according to the water quality.
This analysis can be exported within a detailed report to help users to make decisions about water quality in the catchment.



Figure 7. Thematic map of the water quality

\section{DISCUSSION}

The study has stated the dire need to continuously monitor the quality of our waters. By using the developed GIS Web-based tool, this task will be efficiently carried out. It analyzes the evolution of measured parameters and explains the causes of any changes such as conductivity which has been showed earlier.

Monitoring water quality spatially and at a continuous trend will help identify the local causes of water pollution such as products from a farm or an industry. When this information is put up on the web tool, and shown to the identified stakeholder, since it presents real time data analysis, the stakeholders will be at a position to identify how they are contributing to water pollution and the measures that they can take to prevent any further damage.

The principle advantage of this solution is using open source tools with OGC standards to analyze and generate, in real-time and continuously, water quality maps, reports and statistics against the existing solutions in morocco that needs a manual analysis of measured data.

This study faced limitations such as lack of suitable sensors, very high cost of data collection and that of deployment and a couple of off the shelves limitations.

\section{CONCLUSION}

WSN is very crucial in real time spatial data collection for the applications used in water quality monitoring. When the WSN is integrated with the GIS, it offers an even wider, easier and faster method of monitoring by use of a wider amount of data.

In Morocco, the application of this integration has a very high potential. The country would be able to identify the causes of their water pollution more easily and initiate measures of dealing with these problems at the roots.

Among planned future works, upgrading the GIS web tool to generate models should be on the list. There should be availability of models that can extrapolate the results gathered from the monitoring process since it is challenging and time 
consuming to collect data from each and every outlet or water catchment.

\section{REFERENCES}

Agence du bassin hydraulique du Bouregreg et de la Chaouia, 2012. Le plan directeur de l'aménagement intégré des ressources en eau du bassin hydraulique du Bouregreg et de la Chaouia.

Akyildiz, F., Su, W., Sankarasubramaniam, Y., Cayirci, E. 2002a. Computer Networks 38, pp. 393-422.

Akyildiz, F., Su, W., Sankarasubramaniam, Y., Cayirci, E. 2002b. A survey on sensor networks, Commun. Mag. IEEE, vol. 40, no 8, pp. 102-114.

Ayday, C., Saban, S., 2009 Application of Wireless Sensor Networks with GIS on the Soil Moisture Distribution Mapping.

Ayday C., Safak, S., 2009. Application of wireless sensor networks with GIS on the soil moisture distribution mapping, in Symposium GIS Ostrava.

Bounouira, H., 2007 « Etude des qualités chimiques et géochimiques du bassin versant de Bouregreg », Université Pierre et Marie Curie-Paris VI.

Bounouira, H, 2007. Etude des qualités chimiques et géochimiques du bassin versant de Bouregreg, Université Pierre et Marie Curie-Paris VI.

Capella, J. V., Bonastre, A., R. Ors, et M. Peris, « A Wireless Sensor Network approach for distributed in-line chemical analysis of water », Talanta, vol. 80, no 5, p. 1789-1798, 2010.

Fadil, A., Rhinane, H., Kaoukaya, A., Kharchaf, Y., Alami Bachir, O., 2011. Hydrologic Modeling of the Bouregreg Watershed (Morocco) Using GIS and SWAT Model.

Glasgow, H. B., Burkholder, J. M., Reed, R. E., Lewitus, A. J., Kleinman, J. E., 2004. Real-time remote monitoring of water quality: a review of current applications, and advancements in sensor, telemetry, and computing technologies, J. Exp. Mar. Biol. Ecol., vol. 300, no 1-2, pp. 400-448.

Greenwood, R., Mills, G. A., Roig, B., 2007. Introduction to emerging tools and their use in water monitoring, TrAC Trends Anal. Chem., vol. 26, no 4, pp. 263-267.

Hoover, J. H., Sutton, P. C., Anderson, S. J., Keller, A. C., Designing and evaluating a groundwater quality Internet GIS, 2014. Appl. Geogr., vol. 53, pp. 55-65.

Huma, Z., Harris, R., Geoff V., Mark, R., Neil, C., 2012. The impact of agricultural activities on water quality: A case for collaborative catchment-scale management using integrated wireless sensor networks.

Humenyuk, I., 2005 " Développement des microcapteurs chimiques CHEMFETs pour l'analyse de l'eau », INSA de Toulouse.

Jacquot, A., De Sousa, G., Chanet, J.-P., Pinet, F.,2011. Réseau de capteurs sans fil pour le suivi de l'humidité du sol des vignes
, in ECOTECHS, Capteurs et systèmes de mesures pour les applications environnementales, pp. 7.

Lu, G., Krishnamachari, B., Raghavendra, C., 2004. Workshop on Energy-Efficient Wireless Communications and Networks (EWCN), Held in Conjunction With the IEEE International Performance Computing and Communications Conference (IPCCC).

Mainwaring, A. and others, 2002. Sensor Network for Habitat Monitoring, WSNA'02, Atlanta, Georgia, pp. 88-97, ISBN 158113-589-0

Moumen, A., Oulidi, H. J., Agadi, M., Nehmadou, M., BenDaoud, M., Barich, A., Mridekh, A., Mansouri, B. E., Boutaleb, S., Mohammed, K. B. H., Essahlaoui, A., Eljaafari, S., 2014. A Sensor Web for Real-Time Groundwater Data Monitoring in Morocco, J. Geogr. Inf. Syst., vol. 06, no 06, pp. 613-623.

UNESCO, 2009. Report L'eau dans un monde qui change . 